\title{
Treatment of snoring and sleep apnea syndrome with a removable mandibular advancement device in patients without TMD
}

Eduardo Rollo Duarte', Maria Luiza M. A. Frigério², Orivaldo Tavano³, Paulo César Razuk ${ }^{4}$, Maria Rita de Cássia M. Costa ${ }^{5}$, Carlos Henrique Ferreira Martins ${ }^{6}$, Maurício Serejo Ribeiro7, Éderson A. G. Betiol ${ }^{8}$

Introduction: Among the sleep disorders reported by the American Academy of Sleep, the most common is obstructive sleep apnea-hypopnea syndrome (OSAHS), which is caused by difficulties in air passage and complete interruption of air flow in the airway. This syndrome is associated with increased morbidity and mortality in apneic individuals.

Objective: It was the objective of this paper to evaluate a removable mandibular advancement device as it provides a noninvasive, straightforward treatment readily accepted by patients.

Methods: In this study, 15 patients without temporomandibular disorders (TMD) and with excessive daytime sleepiness or snoring were evaluated. Data were collected by means of: Polysomnography before and after placement of an intraoral appliance, analysis of TMD signs and symptoms using a patient history questionnaire, muscle and TMJ palpation.

Results: After treatment, the statistical analysis (t-test, and the "before and after" test) showed a mean reduction of $77.6 \%(p=0.001)$ in the apnea-hypopnea index, an increase in lowest oxyhemoglobin saturation ( $p=0.05)$, decrease in desaturation ( $\mathrm{p}=0.05)$, decrease in micro-awakenings or EEG arousals $(\mathrm{p}=0.05)$ and highly significant improvement in daytime sleepiness $(\mathrm{p}=0.005)$, measured by the Epworth Sleepiness Scale. No TMD appeared during the monitoring period.

Conclusion: The oral device developed in this study was considered effective for mild to moderate OSAHS.

Keywords: Snoring. Obstructive sleep apnea. Mandibular advancement. Occlusal splints.

${ }^{1}$ Head of the department of Orofacial Pain (TMJ) and Sleep Dentistry, Clinic of Sleep Disorders, Bauru, Brazil.

${ }^{2}$ Assistant Professor, Department of Dental Prosthesis, FOUSP, Brazil.

${ }^{3}$ Head Professor of Department of Surgery and Radiology, Bauru Dental School, FOB-USP, Brazil.

${ }^{4}$ Head Professor, Department of Engineering, UNESP, Bauru, Brazil.

${ }^{5}$ Neurologist and Sleep physician. Head of the Clinic of Sleep Disorders, Bauru, Brazil.

${ }^{6}$ Otolaryngologist, Hospital for Rehabilitation of Craniofacial Anomalies, USP. Head of the Respiratory Department, Clinic of Sleep Disorders, Bauru, Brazil.

${ }^{7}$ Head of Dental Prosthesis, FOC UNIFLU, Rio de Janeiro, Brazil.

${ }^{8}$ Professor of Department of Dental Prosthesis of Paraná Federal University, Curitiba, Brazil.
How to cite this article: Duarte ER, Frigério MLMA, Tavano O, Razuk PC, Costa MRCM, Martins CHF, Ribeiro MS, Betiol EAG. Treatment of snoring and sleep apnea syndrome with a removable mandibular advancement device in patients without TMD. Dental Press J Orthod. 2012 Mar-Apr;17(2):90-6.

Submitted: September 12, 2008 - Revised and accepted: April 26, 2009

» The authors report no commercial, proprietary, or financial interest in the products or companies described in this article.

Contact address: Eduardo Rollo Duarte - Rua Felício Soubihe 3-74, Jd. Planalto CEP: 17.012-623 - Bauru/SP - Brazil - E-mail: edurollo@uol.com.br 


\section{INTRODUCTION}

One often hears that when a person is asleep and snoring, it means that they are fast and sound asleep. It couldn't be farther from the truth. A partial obstruction in the upper airway causes snoring while a complete obstruction leads to sleep apnea, which is the total cessation of airflow. These events comprise what is known as Sleep Apnea and Hypopnea Syndrome (OSHAS) and lead to serious consequences such as systemic and pulmonary hypertension, excessive daytime sleepiness, impaired memory, irritability, depression, decreased libido, impotence, burnout, headache and a proneness to workplace and car accidents. Apnea is characterized by an interruption in airflow (breathing) for at least ten seconds. Hypopnea is a $50 \%$ reduction in airflow accompanied by a "microawakening” or EEG arousal and/or a drop in blood oxyhemoglobin saturation ( $\mathrm{SaO} 2)$ of about $2 \%$ to $4 \% .{ }^{4}$

It is diagnosed by examining sleep with polysomnography (PSG), which consists of simultaneously recording activities occurring in the organism during a given period and tracking not only the number of apneas and hypopneas during the patient's sleep but also defining OSHAS severity using the apnea-hypopnea index (AHI), which is the sum of apnea and hypopnea events per hour of sleep. ${ }^{6}$

Several authors have confirmed the validity and effectiveness of oral appliances for OSHAS treatment. ${ }^{1,2,5,8,9,10,16}$ Appliances that reposition the mandible anteriorly are indicated for primary snoring and mild to moderate OSAHS with an AHI of up to $30^{4,9}$.

In OSAHS patients this therapy can be effective even in the presence of other diseases such as congestive heart failure and arterial hypertension, ${ }^{8,19,30}$ thereby contributing to clinical control.

In treating OSHAS a correct diagnosis is of paramount importance, as well as a multidisciplinary team with training and knowledge of sleep disorders, and a reliable treatment indication for each case. Dentists should be part of this team as they play a key role both in the initial diagnosis, by referring the patient to polysomnography, and in the treatment itself after the examination.

The purpose of this study was to develop an alternative intraoral appliance model for treating OSHAS, evaluate its effectiveness and magnitude of changes in AHI, and observe the side effects and development of potential TMD (temporomandibular dysfunction) signs and symptoms in the follow-up phase.

\section{MATERIAL AND METHODS}

The study evaluated 15 patients among those who presented voluntarily at the Clinic of Sleep Disorders located in Bauru, Brazil, reporting excessive daytime sleepiness and/or snoring. Patients had a mean age of 49.9 years.

Initially, patients answered a questionnaire, the Epworth Sleepiness Scale (ESS), designed to measure their daytime sleepiness in specific situations, ${ }^{15}$ including patients with ESS scores greater than five. Examination to check for the presence of Temporomandibular Disorders (TMD) began with the patient's clinical history using the Anamnesis Index (AI) questionnaire. ${ }^{7,11,18}$ The results were compared with the AI table, which classifies patients' TMD, thus: 0-15, no TMD, 20-40, mild TMD, 45-65, moderate TMD, 70-100, severe TMD. Thereafter, a physical and clinical examination was performed by digital palpation of the right and left TMJs and muscles (superficial and deep masseter, medial pterygoid and temporal). Patient response to TMJ palpation was graded as suggested by Pertes and Gross ${ }^{21}$ and as performed by Miranda. ${ }^{18}$ Therefore, assessment of the development of TMD signs and symptoms was performed by comparing AI before and after treatment, and also by physical examination, i.e., palpation of masticatory muscles and TMJ.

Exclusion criteria were as follows: AI higher than 15 (since subjects with AI between zero and 15 are considered without TMD, and above 15, with TMD) or presence of TMD signs and symptoms, moderate or severe periodontal disease, lower than $6 \mathrm{~mm}$ maximum mandibular protrusion and less than $35 \mathrm{~mm}$ mouth opening.

All patients underwent polysomnography (PSG) in the Clinic of Sleep Disorders before and after wearing the appliance. The average time interval between PSGs was five months.

During fabrication, the adjustable mandibular advancement splints were waxed, made with an opening from canine to canine (1.5 $\mathrm{mm}$ on average) and processed. Stainless steel wires were also used for mechanical support to prevent the acrylic from fracturing. A $13 \mathrm{~mm}$ palate expander screw was 
employed to join the maxillary to the mandibular portion of the splint (Fig 1).

At each visit after splint insertion it was advanced by $0.25 \mathrm{~mm}$ until the mandibular advancements reached $1 \mathrm{~mm}$ within a two-week period. Patients were monitored on a weekly basis and, after reporting an improvement in snoring and sleepiness, were referred for a second PSG. After approximately six months wearing the splint, the patients were examined again to assess TMD development.

The tests used for statistical analysis of the results included Student's t-distribution test for small samples, with degree of freedom (df) lower than 120 and the "before and after" test which, in simple comparative experiments with samples that have the same origin, ensures greater accuracy than t-test. Both tests were applied to ensure outcome reliability.

\section{RESULTS}

Anthropometric data of the subjects who participated in the research are presented in Table 1.

The data were statistically evaluated by Student's t-test and confirmed by the "before and after" test. Assessment results of daytime sleepiness before and after splint use are depicted in Table 2.

All patients exhibited decreased ESS values, noting that the treatment reduced excessive daytime sleepiness in a highly significant manner in $87 \%$ of the patients $(\mathrm{p}=0.005)$.

It is noteworthy that AI variation was not sufficient to affect the TMD classification of any patient, i.e., it did not increase over 15 . On physical examination by
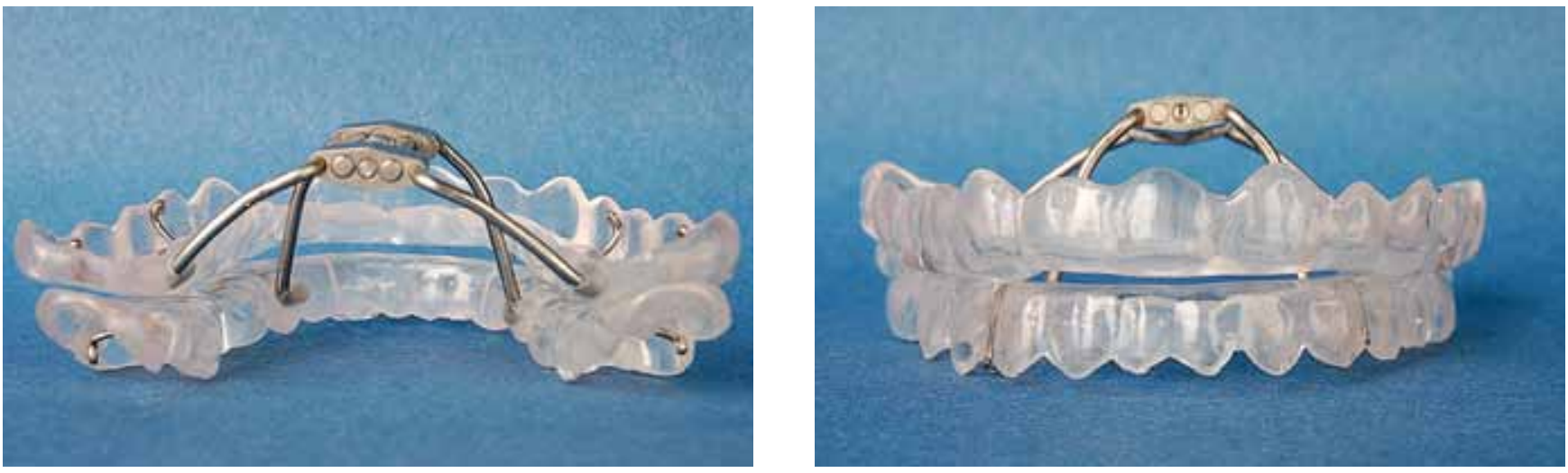

muscle palpation 14 patients showed no significant differences after treatment compared to muscle palpation values found prior to treatment.

During mandibular advancement therapy patients 6 and 15 (13.3\%) developed morning muscle pain. ${ }^{10}$ Treatment included the prescription of oral medication (Celecoxib $200 \mathrm{mg}$ ) once a day for three days. The mandibular advancement was halted for a week and then restarted at $0.25 \mathrm{~mm}$ per week. ${ }^{2}$ The two patients were left with the splint positioned $1 \mathrm{~mm}$ below the $75 \%$ of maximum protrusion mark. These two patients never again exhibited TMD signs and symptoms.

Table 4 presents the oxyhemoglobin saturation index, number of arousals and number of apneas and hypopneas occurring per hour during the first and second PSG.

On the one-tailed Student's table for $\mathrm{p}=0.05$ and $\mathrm{df}=14$, tc $=1.761$ with $95 \%$ confidence for the situation "with splint", the amount of oxyhemoglobin desaturation events decreased significantly.

For the one-tailed test $t c=1.761$ (hence to $>t c$ ), the number of arousals "after" is significantly lower than "before."

Snoring, as evaluated by PSG, improved in all patients to acceptable levels and was suppressed or not observed in patients 4 and 15 (moderate frequency level) and in patients 5 and 8 (high frequency).

AHI before treatment had a baseline mean of 18.3 $(\mathrm{SD}=11.8)$. After treatment, the AHI displayed a mean of 4.1 ( $\mathrm{SD}=3.8, \mathrm{p}=0.001)$. Thus, the outcome for "after" is significantly less than for "before", i.e., there was a highly significant reduction in AHI.

Figure 1 - Adjustable mandibular advancement splints used in patients with OSAHS 
Table 1 - Anthropometric data of research participants.

\begin{tabular}{|c|c|c|c|c|c|c|c|c|}
\hline \multirow{2}{*}{ Subjects } & \multirow{2}{*}{ Gender } & \multicolumn{2}{|c|}{ Age (years) } & \multirow{2}{*}{$\begin{array}{c}\text { Height } \\
\text { (m) }\end{array}$} & \multicolumn{2}{|c|}{ Weight (kg) } & \multicolumn{2}{|c|}{ BMI } \\
\hline & & Before & After & & Before & After & Before & After \\
\hline P1 & Male & 35 & 37 & 1.72 & 83 & 80 & 28 & 27 \\
\hline P2 & Male & 39 & 42 & 1.69 & 102 & 103 & 36 & 36 \\
\hline P3 & Male & 40 & 43 & 1.72 & 78 & 76 & 26 & 26 \\
\hline P4 & Female & 50 & 52 & 1.48 & 51 & 52 & 23 & 24 \\
\hline P5 & Female & 59 & 60 & 1.61 & 70 & 78 & 27 & 30 \\
\hline P6 & Female & 63 & 64 & 1.8 & 97 & 97 & 30 & 30 \\
\hline P7 & Male & 28 & 28 & 1.87 & 114 & 116 & 33 & 33 \\
\hline P8 & Female & 54 & 55 & 1.57 & 69 & 69 & 28 & 28 \\
\hline P9 & Female & 40 & 42 & 1.66 & 63 & 63 & 23 & 23 \\
\hline P10 & Female & 55 & 55 & 1.57 & 94 & 94 & 38 & 38 \\
\hline P11 & Male & 63 & 65 & 1.68 & 92 & 93 & 33 & 33 \\
\hline $\mathrm{P} 12$ & Male & 54 & 56 & 1.69 & 79 & 76 & 28 & 27 \\
\hline P13 & Male & 57 & 58 & 1.58 & 66 & 66 & 26 & 26 \\
\hline P14 & Male & 56 & 57 & 1.67 & 83 & 83 & 30 & 30 \\
\hline P15 & Male & 47 & 47 & 1.68 & 75 & 75 & 27 & 27 \\
\hline
\end{tabular}

Table 2 - Results of the Epworth Sleepiness Scale (ESS) before and after splint use.

\begin{tabular}{|ccc|}
\hline Subjects & Before & After \\
\hline P1 & 8 & 3 \\
P2 & 6 & 2 \\
P3 & 7 & 2 \\
P4 & 11 & 3 \\
P5 & 12 & 6 \\
P6 & 8 & 7 \\
P7 & 14 & 6 \\
P8 & 13 & 10 \\
P9 & 6 & 2 \\
P10 & 6 & 2 \\
P11 & 10 & 5 \\
P12 & 6 & 3 \\
P13 & 10 & 4 \\
P14 & 13 & 3 \\
P15 & 13 & 6 \\
\hline
\end{tabular}

Table 3 - Anamnesis Index (AI) results before and after splint use.

\begin{tabular}{|ccc|}
\hline Subjects & Before & After \\
\hline P1 & 8 & 4 \\
P2 & 6 & 6 \\
P3 & 15 & 0 \\
P4 & 5 & 5 \\
P5 & 15 & 10 \\
P6 & 13 & 7 \\
P7 & 0 & 0 \\
P8 & 3 & 0 \\
P9 & 0 & 0 \\
P10 & 7 & 7 \\
P11 & 6 & 0 \\
P12 & 0 & 0 \\
P13 & 15 & 4 \\
P14 & 15 & 5 \\
P15 & 15 & 5 \\
\hline
\end{tabular}


Table 4 - Oxyhemoglobin saturation index (\%) and number of arousals and obstructive events per hour (AHI).

\begin{tabular}{|c|c|c|c|c|c|c|c|c|}
\hline \multirow{2}{*}{ Subj. } & \multicolumn{2}{|c|}{ Lowest Saturation } & \multicolumn{2}{|c|}{ Desaturation } & \multicolumn{2}{|c|}{ Micro-awakening } & \multicolumn{2}{|c|}{ AHI } \\
\hline & Before & After & Before & After & Before & After & Before & After \\
\hline $\mathrm{P} 1$ & 91.0 & 92.0 & 1.0 & 0.0 & 11.9 & 1.8 & 11.3 & 0.0 \\
\hline P2 & 77.0 & 81.0 & 17.0 & 7.0 & 32.8 & 0.0 & 26.8 & 3.3 \\
\hline P3 & 87.2 & 89.0 & 25.0 & 3.0 & 20.0 & 0.0 & 19.3 & 6.0 \\
\hline P4 & 86.0 & 90.0 & 4.0 & 0.0 & 0.0 & 0.0 & 18.8 & 1.8 \\
\hline P5 & 87.9 & 92.0 & 1.0 & 0.0 & 0.0 & 6.6 & 8.2 & 0.0 \\
\hline P6 & 82.0 & 83.0 & 31.0 & 34.0 & 0.0 & 0.0 & 14.1 & 5.9 \\
\hline P7 & 82.0 & 85.0 & 12.0 & 2.0 & 0.0 & 0.0 & 9.7 & 2.6 \\
\hline P8 & 86.0 & 87.0 & 17.0 & 1.0 & 19.4 & 0.0 & 20.1 & 0.8 \\
\hline P9 & 88.0 & 94.0 & 0.0 & 0.0 & 9.4 & 0.0 & 0.7 & 1.1 \\
\hline P10 & 88.9 & 92.0 & 0.0 & 0.0 & 13.4 & 10.4 & 6.3 & 0.6 \\
\hline P11 & 69.0 & 72.0 & 23.0 & 25.0 & 23.7 & 0.0 & 17.7 & 10.2 \\
\hline $\mathrm{P} 12$ & 85.6 & 88.0 & 8.0 & 4.0 & 64.6 & 12.5 & 53.5 & 9.3 \\
\hline P13 & 77.0 & 83.0 & 47.0 & 32.0 & 0.0 & 0.0 & 22.1 & 6.0 \\
\hline P14 & 77.0 & 83.0 & 30.0 & 1.0 & 0.0 & 0.0 & 19.4 & 2.7 \\
\hline P15 & 81.0 & 82.0 & 24.0 & 12.0 & 30.7 & 0.0 & 26.4 & 11.8 \\
\hline
\end{tabular}

\section{DISCUSSION}

The aim of this study was to evaluate the effectiveness of an adjustable intraoral mandibular advancement splint in the treatment of OSAHS. ${ }^{5,9,19}$

Currently, it is recommended that to be considered successful OSHAS treatment using oral splints must comply with the following polysomnographic parameters: A reduction in AHI of at least $50 \%$ or a reduction in AHI values below ten. ${ }^{16}$

A highly significant reduction in AHI found in 15 patients, i.e., $77.6 \%$ mean reduction, demonstrates that the splints can be indicated for treating snoring, increased upper airway resistance syndrome and OSAHS cases of mild to moderate severity, although some patients with severe OSAHS can also benefit from the therapy, such as patient 12 in this research. When patient 12 was excluded so that the data analysis could be restricted to patients with $\mathrm{AHI}<30$ only, a highly significant improvement in AHI was still found, i.e., a mean $75.9 \%(\mathrm{p}=0.001)$. Nine (81.8\%) out of 11 patients with AHI $>10$ showed a reduction in AHI to values below ten. It was observed that mandibular repositioning caused a reduction in AHI. Upper airway narrowing due to anatomical factors such as a posterior positioning of the mandible is a risk factor for sleep apnea. In advancing the mandible, the splints widen and stretch the muscles, which concurrently produce an increase in electromyographic activity, widening the airway and improving airflow. ${ }^{1,2,14,17,19,26}$

Thirteen patients $(86.7 \%)$ exhibited some degree of tooth sensitivity, especially on awakening in the morning. With splint use, five patients (33\%) complained of excessive salivation at night and one patient (6.6\%) complained of dry mouth at night. In this study, specifically in regard to the development of joint or muscle pain, therapy with splints did not produce definitive or reversible TMD signs or symptoms. Yoshida ${ }^{29}$ found these effects in $8.5 \%$ of cases and described them as transient. None of the participants was diagnosed with TMD prior to treatment, and after treatment completion (12-month followup, on average), no signs or symptoms of TMD-related muscle or joint dysfunction were identified.

It is noteworthy that harmful side effects such as tooth sensitivity (86.7\%), dry mouth or excessive salivation (40\%) occurred after splint placement but on examination were considered minor or mild. ${ }^{12,19,23,24,25}$ 
Authors have indicated that the advancement should be between $50 \%$ and $75 \%$ of maximum mandibular protrusion ${ }^{2}$ since such repositioning would be within the measurements of a physiological mandibular protrusion. ${ }^{22}$ Six patients had muscle pain and two patients (P6 and P15) presented with moderate pain, which prevented further advancement to $75 \%$ maximum protrusion, although the pain was controlled with non-steroidal anti-inflammatory medication. No other changes occurred in AI, indicating no development of TMD signs and symptoms.

The splints were inserted at $60 \%$ maximum protrusion and advanced in increments of $0.5 \mathrm{~mm}$ to 1 $\mathrm{mm}$ within two weeks, unlike other studies, which made weekly advancements of $0.25 \mathrm{~mm} .^{20}$

In this study, the mean mandibular advancement was $9.17 \mathrm{~mm}$, ranging from 7 to $12 \mathrm{~mm}$, therefore within what is considered a physiological protrusion length. These results are similar to several studies that proved the effectiveness of splints in mild and moderate OSAHS. ${ }^{5,9,30}$

Advancement was discontinued based on the following criteria: A position that coincided with $75 \%$ maximum protrusion and improvement in subjective criteria reported by patients. Clinically, however, defining such criteria can prove elusive. Some authors have therefore suggested an association with objective parameters at the end of mandibular advancement therapy, such as nocturnal pulse oximetry performed at home..$^{10,28}$

Reports of improvement in snoring and daytime sleepiness led four patients (26.7\%) to an early referral for a second PSG, but the results showed no change in AHI. This situation showed that the reports of patients and/or of their room-mates are indeed subjective and not a substitute for polysomnography as a therapeutic assessment tool..$^{9,16}$ Further advancements were made in these patients and another PSG was performed for each one, except for patient P11, who refused to repeat it and was the only patient who showed no reduction in AHI above $50 \%$ (42.4\% reduction).

Therapy with the splint caused a direct effect on sleep fragmentation as there was an increase in the lowest oxyhemoglobin saturation index $(\mathrm{p}=0.05)$ and a significant decrease in total desaturation and number of arousals $(\mathrm{p}=0.05)$. Clinically, improvement in polysomnographic parameters was found to be related to a significant decrease $(\mathrm{p}=0.05)$ in $\mathrm{ESS} .{ }^{8,19}$
Improvement in snoring levels was observed in all cases and the subjective assessment of spouse confirmed this result. Spouse satisfaction is extremely important since for him or her snoring can cause another sleep disorder, i.e., insomnia. ${ }^{4}$

Long-term studies are warranted to compare the designs and materials used in the splints and to verify the occurrence of any potential desirable or undesirable effects. ${ }^{3}$ However, even if significant side effects do occur, a thorough evaluation - pinpointing favorable and unfavorable biological factors - should be conducted and discussed to enable treatment decisions that benefit the patient in the best possible way while gaining control over the important and severe complications of OSAHS. Although treatment using a splint is regarded as a non-invasive therapy, side effects are likely to occur during treatment. Occlusal changes may occur with long-term use, so patients should be strictly controlled. ${ }^{27}$

When patients feel the benefits of therapy using the splint and realize that they are waking up feeling rested, they start wearing it on a daily and continuous basis. ${ }^{13}$

Although this splint was fabricated with materials normally used in dental practice (such as acrylic resin), in light of the limitations of this study and the success criteria adopted for the AHI reduction (above 50\%), splint effectiveness was successfully evaluated and the results consistent with those found in the literature.

\section{CONCLUSIONS}

Results indicated that the splint developed for this study proved to be a viable alternative for treatment of mild to moderate OSAHS. Therapy using splints did not developed definitive TMD signs and symptoms during the evaluation period. There was a highly significant reduction in AHI above $50 \%$ in $93.3 \%$ of patients (mean $77.6 \%$ ) an increase in lower oxygen saturation, reduction in desaturation, decreased number of micro-awakenings or EEG arousals, and subjective improvement in snoring and excessive daytime sleepiness. Undesirable effects were considered minimal and controllable, and no definitive TMD signs and symptoms were found to occur. 


\section{REFERENCES}

1. Aarab G, Lobbezoo F, Wicks DJ, Hamburger HL, Naeije M. Short-term effects of a mandibular advancement device on obstructive sleep apnea: an open-label pilot trial. J Oral Rehabil. 2005;32(8):564-70.

2. Almeida FR, Bittencourt LR, Almeida Cl, Tsuiki S, Lowe AA, Tufik S. Effects of mandibular posture on obstructive sleep apnea severity and the temporomandibular joint in patients fitted with an oral appliance. Sleep. 2002;25(5):507-13.

3. Almeida FR, Lowe AA, Otsuka R, Fastlicht S, Farbood M, Tsuiki S. Long-term sequelae of oral appliance therapy in obstructive sleep apnea patients: Part 1 Cephalometric analysis. Am J Orthod Dentofacial Orthop. 2006;129(2):205-13.

4. American Academy of Sleep Medicine. Sleep related breathing disorders in adults: recommendations for syndrome definitions and measurements techniques in clinical research. Sleep. 1999;22:667-89.

5. Barthlen GM, Brown LK, Wiland MR, Sadeh JS, Patwari J, Zimmerman M. Comparison of three oral appliances for treatment of severe obstructive sleep apnea syndrome. Sleep Med. 2000;1(4):299-305

6. Bittencourt LR, Suchecki D, Tufik S, Peres C, Togeiro SM, Bagnato MC, et al. The variability of the apnoea-hypopnoea index. J Sleep Res. 2001;10(3):245-51.

7. Conti PC, Ferreira PM, Pegoraro LF, Conti JV, Salvador MC. A cross-sectional study of prevalence and etiology of signs and symptoms of temporomandibular disorders in high school and university students. J Orofac Pain. 1996 Summer;10(3):254-62.

8. Eskafi M. Sleep apnea in patients with stable congestive heart failure. An intervention study with a mandibular advancement device. Swed Dent J Suppl. 2004:(168):1-56

9. Ferguson KA, Cartwright R, Rogers R, Schmidt-Nowara W. Oral appliances for snoring and obstructive sleep apnea: a review. Sleep. 2006;29(2):244-62.

10. Fleury B, Rakotonanahary D, Petelle B, Vincent G, Pelletier Fleury N, Meyer B, et al. Mandibular advancement titration for obstructive sleep apnea: optimization of the procedure by combining clinical and oximetric parameters. Chest. 2004;125(5):1761-7

11. Fonseca DM, Bonfante G, Valle AL, Freitas SFT. Diagnóstico pela anamnese da disfunção craniomandibular. RGO: Rev Gaúcha Odontol. 1994;42(1):23-8.

12. Gavish A, Vardimon AD, Rachima H, Bloom M, Gazit E. Cephalometric and polysomnographic analyses of functional magnetic system therapy in patients with obstructive sleep apnea. Am J Orthod Dentofacial Orthop. 2001;120(2):169-77.

13. Jauhar S, Lyons MF, Banham SW, Cameron DA, Orchardson R. Ten-year follow-up of mandibular advancement devices for the management of snoring and sleep apnea. J Prosthet Dent. 2008;99(4):314-21.

14. Johal A, Battagel JM. An investigation into the changes in airway dimension and the efficacy of mandibular advancement appliances in subjects with obstructive sleep apnoea. Br J Orthod. 1999;26(3):205-10.

15. Johns MW. A new method for measuring daytime sleepiness: the Epworth Sleepiness scale. Sleep. 1991;14:540-5.
16. Kushida CA. Practice parameters for the treatment of snoring and obstructive sleep apnea with oral appliances: an update for 2005. An American Academy of Sleep Medicine Report. Sleep. 2006;29(2):240-3.

17. Lowe AA, Sjöholm TT, Ryan CF, Fleetham JA, Ferguson KA, Remmers JE. Treatment, airway and compliance effects of a titratable oral appliance. Sleep. 2000;23 Suppl 4:S172-8

18. Miranda JES. Avaliação longitudinal da efetividade das placas oclusais reposicionadoras no controle de patologias da ATM: comparação com placas oclusais estabilizadoras e um grupo controle [tese]. Bauru (SP): Universidade de São Paulo; 2000

19. Ng AT, Gotsopoulos H, Qian J, Cistulli PA. Effect of oral appliance therapy on upper airway collapsibility in obstructive sleep apnea. Am J Respir Crit Care Med. 2003;168(2):238-41. Epub 2003 Apr 30

20. Okawara Y, Tsuiki S, Hiyama S, Hashimoto K, Ono T, Ohyama K. Oral appliance titration and nasal resistance in nonapneic subjects. Am J Orthod Dentofacial Orthop. 2004;126(5):620-2

21. Pertes RA, Gross SG. Clinical management of temporomandibular disorders and orofacial pain. Chicago: Quintessence; 1995. 368 p.

22. Piehslinger E, Celar A, Futter K, Slavicek R. Orthopedic jaw movement observations. Part I: determination and analysis of the length of protrusion. Cranio. 1993;11(2):113-7.

23. Ringqvist $M$, Walker-Engström ML, Tegelberg A, Ringqvist I. Dental and skeletal changes after 4 years of obstructive sleep apnea treatment with a mandibular advancement device: a prospective, randomized study. Am J Orthod Dentofacial Orthop. 2003;124(1):53-60

24. Ryan CF, Love L, Peat D, Fleetham J, Lowe A. Mandibular advancement oral appliance therapy for obstructive sleep apnoea: effect on awake calibre of the velopharynx. Thorax. 1999;54(11):972-7.

25. Schmidt-Nowara W. Recent developments in oral appliance therapy of sleep disordered breathing. Sleep Breath. 1999;3(3):103-6

26. Tsuiki S, Ryan CF, Lowe AA, Inoue Y. Functional contribution of mandibular advancement to awake upper airway patency in obstructive sleep apnea. Sleep Breath. 2007;11(4):245-51

27. Ueda H, Almeida FR, Lowe AA, Ruse ND. Changes in occlusal contact area during oral appliance therapy assessed on study models. Angle Orthod 2008:78(5):866-72

28. Wiltshire N, Kendrick AH, Catterall JR. Home oximetry studies for diagnosis of sleep apnea/hypopnea syndrome: limitation of memory storage capabilities. Chest. 2001:120(2):384-9.

29. Yoshida K. Effect of a prosthetic appliance for treatment of sleep apnea syndrome on masticatory and tongue muscle activity. J Prosthet Dent. 1998:79(5):537-44.

30. Yoshida K. Effect on blood pressure of oral appliance therapy for sleep apnea syndrome. Int J Prosthodont. 2006;19(1):61-6. 